\title{
A Clinical Audit of Intrapartum Care in Third Stage of Labor
}

\author{
Harshitha $\mathrm{S}^{1}, \mathrm{R}$ Nagarathnamma², MPA Sailakshmi ${ }^{3}$
}

\begin{abstract}
Introduction: The third stage of labor is the time from the birth of the baby to the expulsion of the placenta and membranes. Management are normally categorized into two types; active management and physiological management. Active management of the third stage involves a package of care comprising the following components: routine use of uterotonic drugs, deferred clamping and cutting of the cord controlled cord traction after signs of separation of the placenta. Most common complications of third stage of labor are postpartum hemorrhage and retained placenta.
\end{abstract}

Aims and objectives: The present clinical audit aims to improve the care of healthy women and their babies during the third stage of child and to review the practices regarding the third stage of labor and to develop and implement action plan regarding management strategies.

Materials and methodology: The audit was carried out on 218 pregnant women admitted in RajaRajeswari Medical College and Hospital from April 2018 to September 2018. The inclusion criteria, exclusion criteria and data collection on excel sheet were based on NICE guidelines. Results: Among 218 cases, vaginal blood loss was recorded in $181(83 \%)$ cases whereas the color, respiration and general condition was recorded in all 218 cases. Active management of third stage was carried out and decision regarding the same was recorded in all 218 cases. The time of cord clamping was recorded in only $6 \%$ of the cases. The management of PPH and retained placenta met audit standard in all 218 cases. Conclusion and recommendations: The present clinical audit suggests that there is a need to follow specific guidelines and treatment strategies to avert the complications. Recording of vaginal blood loss in all cases, instructions for compulsory recording of the cord clamping time following birth of baby and continue to follow the remaining steps according to NICE guidelines to reduce the complications of third stage of labor.

Keywords: NICE guidelines, PPH, Uterotonics.

The Journal of Medical Sciences (2019): 10.5005/jp-journals-10045-00108

\section{INTRODUCTION}

The third stage of labor is the time from the birth of the baby to the expulsion of the placenta and membranes. "This indeed is the unforgiving stage of labor, and in it there lurks more unheralded treachery than in both the other stages combined. The normal case can, within a minute to become abnormal and successful delivery can turn swiftly to disaster." Management of third stage are categorized into two types: active management and physiological management.

Active management of the third stage involves following components: routine use of uterotonic drugs, deferred clamping and cutting of the cord controlled cord traction after signs of separation of the placenta. ${ }^{\text {P }}$ Physiological management of the third stage involves the following components: no routine use of uterotonic drugs, no clamping of the cord until pulsation has stopped, delivery of the placenta by maternal effort.

Most common complications of third stage of labor are postpartum hemorrhage, retained placenta and uterine inversion. $\mathrm{PPH}$ is the loss of more than $500 \mathrm{~mL}$ of blood following delivery of the baby. Most bleeding comes from where the placenta was attached to the uterus, and is bright or dark blood and usually thick. PPH occurs when the uterus fails to contract well, usually due to partially or completely separated placenta or atonic uterus. Retained placenta when placenta remains inside the uterus for longer than $\mathbf{3 0}$ min after delivery of the baby. Uterine inversion when the uterus is pulled "inside out" as the baby or the placenta is delivered, and partly emerges through the vagina.

Active management of third stage of labor (AMTSL) involves interventions to assist in expulsion of the placenta with the intention to prevent or decrease blood loss and minimize the complications. Advise the woman to have active management of the third stage, because it is associated with a lower risk of a postpartum hemorrhage and/or blood transfusion. For active
${ }^{1-3}$ Department of Obstetrics and Gynecology, RajaRajeswari Medical College \& Hospital, Bengaluru, Karnataka, India

Corresponding Author: Harshitha S, Department of Obstetrics and Gynecology, RajaRajeswari Medical College \& Hospital, Bengaluru, Karnataka, India, e-mail: hshivu9@gmail.com

How to cite this article: Harshitha S, Nagarathnamma R, Sailakshmi MPA. A Clinical Audit of Intrapartum Care in Third Stage of Labor. J Med Sci 2019;5(1):26-30.

Source of support: Nil

Conflict of interest: None

management, administer 10 IU of oxytocin by intramuscular injection with the birth of the anterior shoulder or immediately after the birth of the baby and before the cord is clamped and cut. Use oxytocin as it is associated with fewer side effects than oxytocin plus ergometrine. After administering oxytocin, clamp and cut the cord: do not clamp the cord earlier than 1 minute from the birth of the baby unless there is concern about the integrity of the cord or the baby has a heart rate below 60 beats/minute that is not getting faster. Clamp the cord before 5 minutes in order to perform controlled cord traction as part of active management.

After cutting the cord, use controlled cord traction. Perform controlled cord traction as part of active management only after administration of oxytocin and signs of separation of the placenta. Record the timing of cord clamping in both active and physiological management.

In case of postpartum hemorrhage, bolus of one of the following as first-line treatment for postpartum hemorrhage oxytocin (10 IU intravenous (IV)) or ergometrine $(0.5 \mathrm{mg}$ intramuscular (IM)) or combined oxytocin and ergometrine (5 IU/ $0.5 \mathrm{mg} I \mathrm{M})$ as first line of treatment. If the bleeding persists repeat

(0) The Author(s). 2019 Open Access This article is distributed under the terms of the Creative Commons Attribution 4.0 International License (https://creativecommons. org/licenses/by-nc/4.0/), which permits unrestricted use, distribution, and non-commercial reproduction in any medium, provided you give appropriate credit to the original author(s) and the source, provide a link to the Creative Commons license, and indicate if changes were made. The Creative Commons Public Domain Dedication waiver (http://creativecommons.org/publicdomain/zero/1.0/) applies to the data made available in this article, unless otherwise stated. 
bolus of oxytocin (IV) orergometrine (IM, or cautiously IV) or combined oxytocin and ergometrine (IM) are given. Other drugs like misoprostol, oxytocin infusion and carboprost (IM) are also used. Adjuvants such as tranexemic acids can also be administered. If the hemorrhage still persists then evaluation under anesthesia should be considered. Ballon tamponade is considered before proceeding with surgical options.

In case retained placenta, vaginal examination to assess the need for manual removal of placenta and manual removal of placenta under anesthesia is carried out. All the above mentioned steps pf active management is as per NICE guidelines. ${ }^{1}$

\section{Materials and Methodology}

The audit was carried out on 218 pregnant women admitted in the Department of Obstetrics in RajaRajeswari Medical College and Hospital from April 2018 to September 2018. The inclusion and exclusion criteria were based on NICE guidelines for clinical audit in intrapartum care in third stage of labor.

\section{Inclusion Criteria}

- Healthy women receiving intrapartum care during the third stage of labor.

\section{Exclusion Criteria: ${ }^{1}$}

- Women in suspected or confirmed preterm labor (before 37 weeks of gestation)

- Women with an intrauterine fetal death

- Women with coexisting severe morbidities such as preeclampsia (high blood pressure of pregnancy) or diabetes.

- Women who have multiple pregnancies

- Women with intrauterine growth restriction of the fetus.

- Women with labor induced

- Women who have cesarean birth

- Women with breech presentation.

Data collection was done using a printed form and the findings were tabulated into the the excel sheet of clinical audit tool third stage of labor from NICE guidelines (Fig. 1).

\section{Tool Includes}

- Clinical audit standards based on the NICE guideline for intrapartum care.

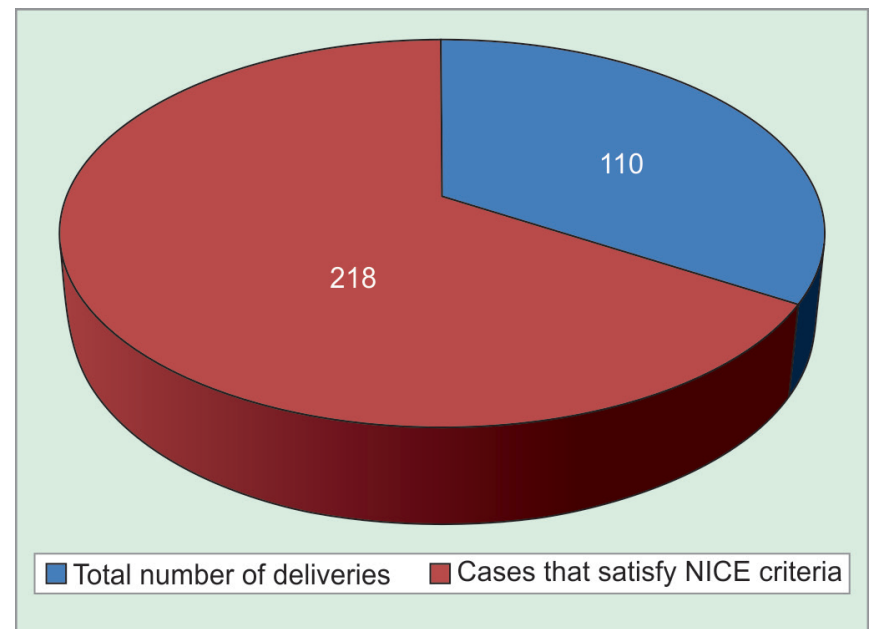

Fig. 1: Clinical audit tool as per the NICE guidelines
- A data collection sheet in which audit data can be entered.

- A clinical audit report that provides basic information about the audit and automatically displays the audit results.

- An action plan template.

- An appendix containing a printable data collection form.

The data collection sheet includes recording of the general physical condition, as shown by their color, respiration and their report of how they feel and vaginal blood loss. The vaginal blood loss was estimated by placing a shallow bedpan below the mother's buttocks, and then weighs the collected blood, along with blood that has soaked into any pads and material. This is referred to as an indirect method. ${ }^{1}$ The mode of management whether active or physiological was noted. If active the use of oxytocin or any other uterotonics were recorded. Timing of cord clamping and delivery of placenta noted. Complications such as postpartum hemorrhage (PPH) and retained placenta if observed were noted and mode of management were recorded. The above data were tabulated into the clinical audit tool on excel sheet. The results were generated automatically on the excel sheet provided by NICE (Tables 1 and 2).

Below is the printable data collection sheet used for recording patient details and steps during third stage of labor. ${ }^{1}$

\section{Results}

Out of 1010 deliveries conducted in RajaRajeswari Medical College during the study period of 6 months, 218 cases satisfied the criteria for clinical audit tool according NICE guidelines.

Among the 218 deliveries, the woman's general physical condition, as shown by her color, respiration and her report of how she feels was recorded in all the 218 cases. Vaginal bloss was recorded by indirect method in 181 cases which was $83 \%$ of the study population. Thus only $83 \%$ of the patient care met audit standard 1 . The decision about the management of the third stage of labor was recorded in all 218 cases which was $100 \%$ and met the standards of audit 2 . All 218 patients had active management of third stage of labor and 218 of them were given injection oxytocin $10 \mathrm{IU}$ intramuscularly immediately after delivery of anterior shoulder. $100 \%$ of the cases met audit standard 3. The time of cord clamping was recorded only in 14 cases which accounted for $6 \%$ of the cases. Thus only $6 \%$ of the cases met audit standard 4 . As only early cord clamping in cases of Rh negative pregnancy were recorded, none of the cases met audit standards of 5 . The third stage of labor was completed within 30 $\min$ in 211 cases that is in $95 \%$ of the cases. The remaining 11 cases needed further intervention and intravenous line was secured in all 11 cases. In $82 \%$ of the above cases intravenous oxytocin was given whereas in the remaining 2 cases methylergometrine was given. Among the 11 cases 9 of them had excessive bleeding and needed oxytocics for further management. The remaining 2 cases had retained placenta and needed manual removal of the placenta under anesthesia. Hence the audit standards of 6, 7 and 9 were met in all the 11 cases with complications. The audit standards of 8 were met in all the cases as the patients were already in obstetric unit.

\section{Discussion}

The main aim of care during the third stage of labor is to prevent postpartum hemorrhage and retained placenta. In the present audit, the audit 1 standards were met in $83 \%$ of the patients. Among the 218 deliveries, the woman's general physical condition, as shown by her color, respiration and her report of how she feels 
Table 1: Use this printable data collection form if you want to complete 1 paper-based data collection form per patient

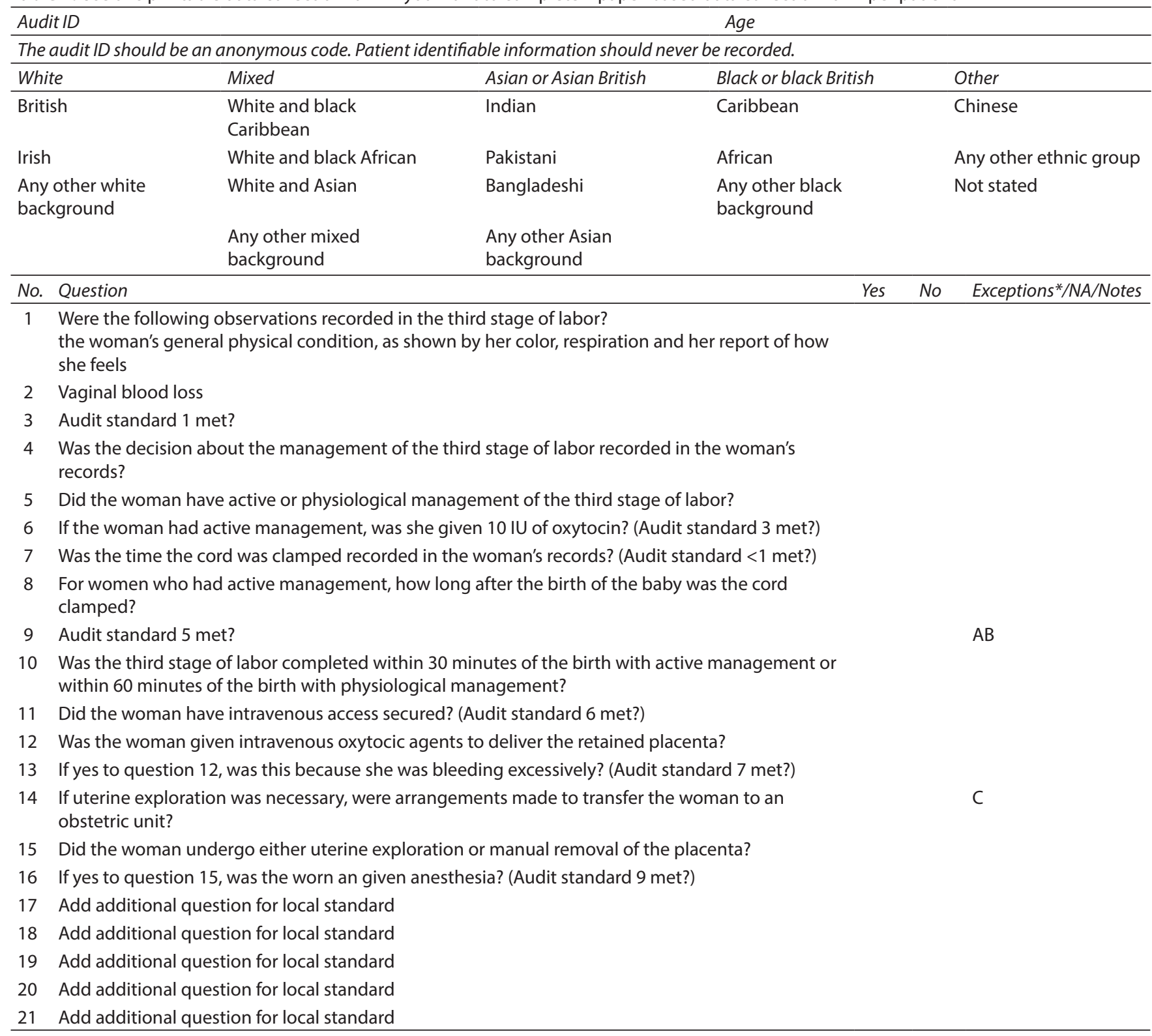

\section{*Exception codes}

A-When there is concern about the integrity of the cord or the baby has a heartbeat below 60 beats/minutes that is not getting faster $\mathrm{B}$-Where a woman requests that the cord is clamped and cut later than 5 minutes

C-Women already in an obstetric unit

was recorded in all the 218 cases. Vaginal blood was recorded in 181 patients. Hemorrhage remains one of the leading causes of maternal mortality. In developing nations, where the vast majority of maternal deaths occur, the problem is exponentially greater. Postpartum hemorrhage has traditionally been defined as an estimated blood loss exceeding $500 \mathrm{~mL}$. Underestimation of peripartum blood loss and delayed blood component therapy seem to be common factors in many cases of avoidable hemorrhagerelated maternal mortality. Inaccurate blood loss assessment can result in significant adverse sequelae and delay in management of postpartum hemorrhage. In the present audit recording of the vaginal blood loss was missed in $13 \%$ of the patients. This can be improved by strict documentation and teaching proper and convenient method of estimating the blood loss for the nurses, interns and residents in the delivery room. This can help achieve the target of $100 \%$ for audit standard 1 .

The decision regarding management of third stage of labor was recorded in $100 \%$ of the cases. All 218 patients consented for active management of labor with intramuscular oxytocin injection after delivery of anterior shoulder and placental expulsion by controlled cord traction. Active management is preferred due to shortening of third stage of labor and reduces the risk of postpartum hemorrhage and need for blood transfusion. In a study conducted by Prendiville et al. $^{2}$ in 4709 women in third stage of labor reduction in incidence of postpartum hemorrhage from 7 to $5 \%$ under physiological management to $5 \%$ under active management and also it shortened the third stage of labor and need for blood transfusion. In another study conducted by Begley 
Table 2: Audit standards as per the NICE guidelines

\begin{tabular}{|c|c|c|}
\hline \multirow{2}{*}{$\begin{array}{l}\text { Audit standards } \\
\text { Observations in the third stage }\end{array}$} & \multicolumn{2}{|c|}{ Audit results } \\
\hline & & \\
\hline $\begin{array}{l}\text { 1. All women in the third stage of labor have the following observations recorded: } \\
\text { - Their general physical condition, as shown by their color, respiration and their report of how they feel } \\
\text { - Vaginal blood loss }\end{array}$ & $83 \%$ & $181 / 218$ \\
\hline \multicolumn{3}{|l|}{ Active and physiological management of the third stage } \\
\hline $\begin{array}{l}\text { 2. All women have documented in their records the decision that is agreed with the woman about active or } \\
\text { physiological management of the third stage of labor. }\end{array}$ & $100 \%$ & $218 / 218$ \\
\hline 3. All women who have active management of the third stage of labor have $10 \mathrm{IU}$ of oxytocin. & $100 \%$ & $218 / 218$ \\
\hline 4. All women have the time the cord was clamped recorded in their records. & $6 \%$ & $14 / 218$ \\
\hline $\begin{array}{l}\text { 5. All women who have active management of the third stage of labor have the cord clamped no earlier than } \\
1 \text { minute from the birth of the baby and no later than } 5 \text { minutes. }\end{array}$ & $0 \%$ & $0 / 218$ \\
\hline \multicolumn{3}{|l|}{ Retained placenta } \\
\hline 6. All women with a retained placenta have intravenous access secured. & $100 \%$ & $11 / 11$ \\
\hline 7. Women are given intravenous oxytocic agents to deliver a retained placenta only if they are bleeding excessively. & $82 \%$ & $9 / 11$ \\
\hline $\begin{array}{l}\text { 8. All women for whom uterine exploration is necessary have arrangements made for urgent transfer to } \\
\text { an obstetric unit. }\end{array}$ & $\%$ & $0 / 0$ \\
\hline 9. All women undergoing uterine exploration or manual removal of the placenta are given anesthesia. & $100 \%$ & $2 / 2$ \\
\hline
\end{tabular}

et al. $^{3}$ in 2010 on 6486 women active management reduced the average risk of maternal primary hemorrhage (more than $1000 \mathrm{~mL}$ ) (risk ratio (RR) $0.34,95 \%$ confidence interval $(\mathrm{Cl}) 0.14$ to 0.87 , three studies, 4636 women) and of maternal hemoglobin less than $9 \mathrm{~g} / \mathrm{dL}$ following birth (RR $0.50,95 \% \mathrm{Cl} 0.30-0.83$, two studies, 1572 women) for women irrespective of their risk of bleeding. Intramuscular oxytocin was administered in all 218 cases and hence audit 3 standard were met. In a study conducted by Elbourne et al. ${ }^{4}$ in 2001 on 3000 women in hospital, prophylactic oxytocin showed benefits (reduced blood loss (relative risk (RR) for blood loss $>500 \mathrm{~mL} 0.50 ; 95 \%$ confidence interval $(\mathrm{Cl}) 0.43,0.59)$ and need for therapeutic oxytocics compared to no uterotonics. Also oxytocin has fewer side effects compared to other uterotonics.

The time of cord clamping was recorded in only $14(6 \%)$ of the cases and failed to meet the audit standard 5. The timing of cord clamping is very important. Early cord clamping in term newborns results in a decrease of $20-40 \mathrm{~mL} / \mathrm{kg}$ of blood, which is equivalent to $30-35 \mathrm{mg}$ of iron. A delay in clamping, causing increased neonatal blood volume, may lead to complications such as respiratory distress, neonatal jaundice, and polycythemia. According to NICE guidelines cord clamping should be after 1 minute and before 5 minutes after the birth of the baby. A systematic review and meta-analysis comparing cordclamping done early ( $<1$ minute after delivery of the infant) and late (at least 2 minutes after delivery) showed that late clamping conferred physiological benefit to the newborn that extended up to 6 months into infancy. Advantages included prevention of anemia over the first 3 months of life and enhanced iron stores and ferritin concentration for up to 6 months. There was no increase in respiratory distress, defined as tachypnea or grunting. Neonates were at increased risk of asymptomatic polycythemia. There was no significant difference between the early and late groups in bilirubin levels and proportions of infants receiving phototherapy. A 2004 Cochrane Review by Rabe et al. ${ }^{5}$ and a prospective study by Ibrahim et al. demonstrated that delaying cord clamping by $30-120$ seconds resulted in less need for transfusion because of anemia and less intraventricular hemorrhage. Therefore the residents and nurses working in the delivery room should be given instructions for cord clamping as per NICE guidelines that is all women who have active management of the third stage of labor have the cord clamped no earlier than 1 minute from the birth of the baby and no later than 5 minutes and document the same in the patient records. This helps in reducing the neonatal complications as mentioned in the above studies. Exception being when there is concern about the integrity of the cord or the baby has a heartbeat below 60 beats/minutes that is not getting faster and where a woman requests that the cord is clamped and cut later than 5 minutes.

In the present study out of 218 cases, in 207 cases active management of third stage of labor lasted for more than 30 minutes. Among the 11 cases, 9 of them had postpartum hemorrhage and 2 of them had retained placenta. Out of 9 cases, 7 of them were given intravenous oxytocin to reduce PPH and the remaining 2 cases were given methylergometrine. The intravenous access was secured in all 11 cases. The cases with retained placenta were managed under anesthesia by manual removal of placenta. The present study met with the audit standards 6,7 and 9. The audit standard 8 was an exception as the patient was already in obstertric unit. According to NICE guidelines, if a woman has a postpartum hemorrhage call for help and give immediate clinical treatment. Firstly by emptying of the bladder followed by uterine massage, uterotonic drugs, intravenous fluids and controlled cord traction if the placenta has not yet been delivered. Continuously assess blood loss and the woman's condition, and identify the source of the bleeding and give supplementary oxygen. Administer a bolus of one of the following as first-line treatment for postpartum hemorrhage: oxytocin (10 IU IV) or ergometrine (0.5 mg IM) orcombined oxytocin and ergometrine (5 IU/0.5 mg IM). Offer second-line treatment for postpartum hemorrhage if needed. No particular uterotonic drug can be recommended over any other; options includes repeat bolus of oxytocin (IV)/ergometrine (IM, or cautiously IV)/combined oxytocin and ergometrine (IM)/ misoprostol/oxytocin infusion/carboprost (IM). Adjuvents like tranexamic acid can also be used. If the hemorrhage continues examination under anesthetic should be considered to ensure that the uterus is empty and repair any trauma. Consider balloon tamponade before surgical options. 


\section{Conclusion}

A major strength of regular clinical audits is that they bring practitioners together frequently to discuss the management of severe cases and to define relevant improvement objectives appropriate to the local context and based on the audit's findings. The present clinical audit suggest that room for improvement exists. There is a need to follow specific guidelines and treatment strategies to avert the complications during third stage of labor. Severe PPH can lead to poor health for the mother (maternal morbidity), and sometimes even death, particularly in low- and middle-income countries. If excessive blood loss is identified early, interventions to help stem the blood flow can be started sooner, and improve health outcomes for the mother.

\section{References}

1. NICE guidelines 2018: Care in the third stage of labour.

2. Prendiville WJ, Harding JE, Elbourne DR, et al. The Bristol third stage trial: active versus physiological management of third stage of labour. Bmj. 1988 Nov 19;297(6659):1295-1300.

3. Begley CM, Gyte GM, Murphy DJ, et al. Active versus expectant management for women in the third stage of labour. Cochrane Database Syst Rev. 2010(7).

4. Elbourne DR, Prendiville WJ, Carroli G, et al. Prophylactic use of oxytocin in the third stage of labour. Cochrane Database Syst Rev. 2001(4):CD001808. DOI: 10.1002/14651858.CD001808.

5. Diaz V, Abalos E, Carroli G. Methods for blood loss estimation after vaginal birth. Cochrane Database Syst Rev. 2018;9. 